\title{
Development of Rwanda's Future Energy Scenarios for Long-Term Investment and Planning
}

\author{
Emmanuel Mudaheranwa, G.Masengo, Ye-Obong Odokah, Liana Cipcigan, Carlos E. Ugalde-Loo \\ Cardiff University \\ Cardiff, United Kingdom \\ mudaheranwae@cardiff.ac.uk
}

\begin{abstract}
This paper supports the development of Rwanda's energy system and addresses gaps in existing energy data by proposing a set of Future Energy Scenarios (FES). The developed FES are used to estimate the energy consumption and generation capacity until 2050. They consider key social, political and economic factors, the diversity of energy generation technologies and regional integration of these technologies and are based on the country's strategies in adopting low carbon technologies. Results for each FES are analyzed, with evidence supporting that reaching net-zero carbon emission targets by 2050 is achievable. However, such an outcome requires the retirement of fossil fuel-based power plants and an immediate adoption of electric vehicles in the transport system.
\end{abstract}

Index Terms-Basic progression, $\mathrm{CO}_{2}$ emission, electric vehicles, high progression, future energy scenarios, medium progression, sustainability.

\section{INTRODUCTION}

Energy systems are rapidly transforming, with change driven by political, economic, environmental, technological and consumer pressures. Although Rwanda has considerable natural energy resources such as hydro, solar, peat, gas, and biomass, it currently has only about 226.7 MW of installed electricity capacity to serve the whole nation [1]. Despite substantial economic growth, it has a low per capita gross domestic product (GDP) of US\$ 696 and a low per capita electricity consumption ( $30 \mathrm{kWh}$ ) compared to other countries of the East Africa Community (EAC), the geographical region where Rwanda is located. For instance, the per capita electricity consumption in Uganda is $66 \mathrm{kWh}$, in Kenya it is $140 \mathrm{kWh}$, and in Tanzania it is $85 \mathrm{kWh}$.

According to Power Africa [2], the Government of Rwanda, under its Economic Development and Poverty Reduction Strategy (EDPRS), had envisioned transitioning from a developing country to a middle-income country by 2020. However, this ambitious goal has been constrained by challenges in the power sector. It was found that since 2008, the power supply had grown by only $10 \%$, while the annual peak demand had grown from approximately from 50 to 87.9 MW (approximately 76\% growth) in 2013 [2]. Rwanda has an annual consumption of electricity per capita among the lowest in Africa, where approximately half of consumers use an average of $<20 \mathrm{kWh}$ per month despite the large availability of resources and opportunities for cross-border electricity import and export.

In its EDPRS II Energy Sector Strategic Plan, the Ministry of Infrastructure (MININFRA), which leads the country's national energy policy, outlined a list of projects through which Rwanda could have reached an installed capacity of about 619 MW by 2018 [3]. In this strategic planning exercise, an additional power generation of $70 \mathrm{MW}$ was planned to be available by the fiscal year 2013/2014 whereas for the fiscal years 2014/2015, 2015/2016, 2016/2017, and 2017/18, the planned power generations were of $29 \mathrm{MW}, 51 \mathrm{MW}, 90 \mathrm{MW}$, and $260 \mathrm{MW}$ respectively. Key information is summarized in Table I, with the demand projected to reach 470 MW by 2018.

TABLE I. Pl. PANNED GENERATION ROADMAP TO ACHIEVE $619 \mathrm{MW}$ OF INSTALLED CAPACITY [3]

\begin{tabular}{|c|c|c|c|}
\hline \multicolumn{3}{|c|}{ Installed Capacity by June 2013} & $119 \mathrm{MW}$ \\
\hline \multirow{4}{*}{ 2013/2014 } & Hydro & 20 & \multirow{4}{*}{$119+70=189$} \\
\hline & Methane & 25 & \\
\hline & Solar & 10 & \\
\hline & Peat & 15 & \\
\hline \multirow{2}{*}{$2014 / 2015$} & Hydro & 25 & \multirow{2}{*}{$189+29=218$} \\
\hline & Methane & 4 & \\
\hline \multirow{5}{*}{$2015 / 2016$} & Peat & 15 & \multirow{5}{*}{$218+51=269$} \\
\hline & Existing & -20 & \\
\hline & Hydro & 6 & \\
\hline & Import & 40 & \\
\hline & Geothermal & 10 & \\
\hline \multirow{3}{*}{$2016 / 2017$} & Methane & 50 & \multirow{3}{*}{$269+90=359$} \\
\hline & Hydro & 10 & \\
\hline & Peat & 30 & \\
\hline \multirow{3}{*}{$2017 / 2018$} & Peat & 200 & \multirow{3}{*}{$359+260=619$} \\
\hline & Hydro & 10 & \\
\hline & Geothermal & 50 & \\
\hline & & & 619 \\
\hline
\end{tabular}


However, as of July 2018, MININFRA estimated that the installed capacity was of $218 \mathrm{MW}$, with $212.5 \mathrm{MW}$ being generated and an import option of 5.5 MW [3]. The installed capacity is divided as follows: hydro with $45 \%$, diesel $27 \%$, methane gas $15 \%$, peat $7 \%$ and solar $6 \%$. Although this has doubled in 8 years since 2010, as shown in Fig. 1, there is a big difference compared to data in Table I.

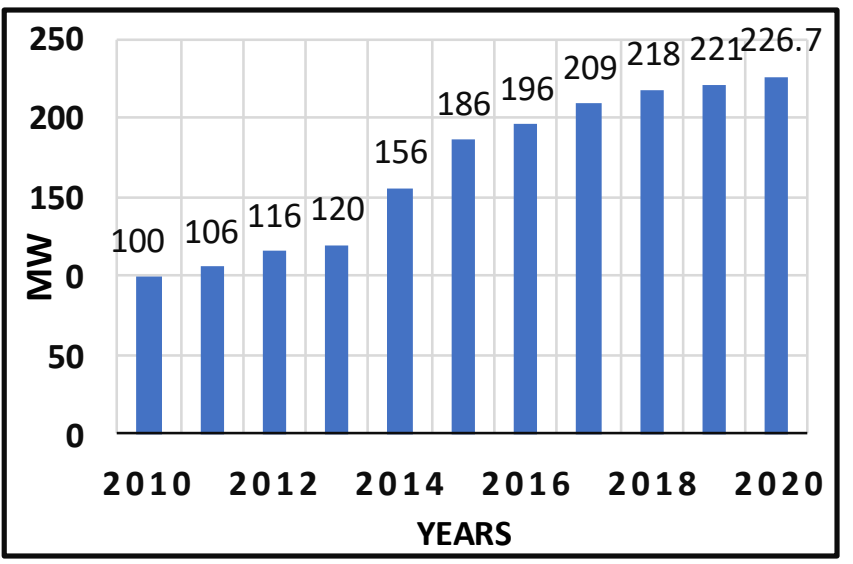

Fig 1. Evolution in installed capacity in Rwanda since 2010 [4].

In [5], the energy outlook in Rwanda was analyzed and it was projected that the total electricity consumption would increase from about $379 \mathrm{GWh}$ in 2012 to around $1000 \mathrm{GWh}$ by 2020. However, records of the Rwanda Energy Group (REG) show a total annual demand of around $870 \mathrm{GWh}$ only by 2020. A mismatch between the annual records and the projections of electricity consumption in [5] account for a mismatch of around $13 \%$.

To contribute towards the energy outlook in Rwanda, this paper presents a set of 2050 FESs, which could be used as a starting point for long-range energy planning. The proposed FES also define a path for the delivery of low-cost energy for future consumers, while improving the contribution of the energy industry to carbon emission reduction technologies. The key variables contributing to the development of the FES include socio-political and economic factors, diversity of energy, regional integration, advanced technologies, and environmental impact. Three scenarios have been developed, but they are not by themselves a forecast of the expected pathways. The actual pathway could be a combination of these scenarios, or any of them independently. The FES are expected to allow Rwanda's government to explore different options and opportunities for the future of its energy system. The projections of energy demand and supply are not limited by capability or operability issues for either the distribution or transmission networks. They are simply based on a view of underlying demand. The developed FES reflect a mix of technology options for a period of 30 years.

\section{ASSUMPTIONS AND QUANTIFICATION OF KEY FACTORS FOR FES DEVELOPMENT}

The personal and collective decisions made by the government and the public at large are the most important factors that may influence the choice of the future energy system.
Personal decisions are based on: (i) the attitude of people towards converting their energy consumption to low emission, (ii) eliminating unnecessary energy use due to change in behaviours, and (iii) financial issues.

Based on social, political and economic influences, the diversity of energy generation technologies, regional integration, and $\mathrm{CO}_{2}$ emissions, a number of energy consumption and generation capacity scenarios are defined considering a time frame from 2019 to 2050 with 2019 as the base year.

1) Basic Progression: Fast urbanization and fast growth in electricity access are the most important factors in this scenario. The number of households in the urban area was expected to grow from 586,000 in year 2019 [6] at $4.1 \%$ per year as referred in the national urbanization policy [7]. Household income is also assumed to rise and, therefore, people purchase inefficient larger appliances with a high utilization time. Based on data from [8], the annual refrigeration intensity is assumed to increase to $150 \mathrm{kWh}$ per household by 2050 , the annual lighting intensity is expected to increase to $410 \mathrm{kWh}$ per household, and the use of other electricity-based equipment (radio and television receivers, computers and mobile phones) is assumed to grow rapidly at a rate of $2.5 \%$ per year [9], [10].

In rural areas, the rural electrification program is expected to increase the percentage of electrified households to $100 \%$ by 2024 and the energy intensity of electric lighting is assumed to increase by 5\% per year [9]. Electrified households with refrigerators in rural areas are assumed to increase to $10 \%$ by 2025 and to $35 \%$ by 2050 , while those with electric stoves are assumed to increase to $25 \%$ by 2050 [8], [9], [11]. The remaining rural households are assumed to use charcoal and wood stoves.

The Rwanda Development Board (RDB) is setting an ambitious policy for industrial development. The most prioritized industries are the manufacturing and tea processing sectors. Construction material (mostly steel and roofing sheets) is the largest and fastest-growing component of Rwanda's manufacturing sector due to the fast urbanization [6]. It is estimated that the industrial output for steel will increase to 100,000 tons by 2050 while the tea, which is expected to be the most exported product, will increase to 40,000 tons by 2050 . The output from other industries is estimated to increase to 80 million USD [12].

In the assumptions used for this scenario, the average process energy for steel production is assumed to be $20 \mathrm{GJ}$ per ton, which is produced by boilers using coal. Each ton of steel requires an average of $2.2 \mathrm{GJ}$ of electricity use [13], [14], [15]. An average tea processing energy of 45 GJ per ton from wood-fired boilers is assumed to be available and each ton of tea requires $9.3 \mathrm{GJ}$ of electricity use. The energy use for other industries is estimated to be $100 \mathrm{GJ}$ with $45 \%$ from electricity, $50 \%$ from wood and the remainder from residual fuel oil [12]. The transport sector development is expected to be aligned to the EDPRS for the country. This scenario considers roads either for passenger or freight transport, and it is estimated that 
the energy efficiency of such transport slowly improves by $0.1 \%$ per year through 2050 [16].

The electricity generation technologies based on hydro, solar, diesel, biomass, methane, and peat are considered in this scenario to estimate how the generation mix is likely to evolve towards 2050. The capacity of diesel power plants is assumed to increase from 58 to $90 \mathrm{MW}$, where a $15 \mathrm{MW}$ plant is to be incorporated by 2030, and the remaining $17 \mathrm{MW}$ are assumed to be added by 2050 [13], [17].

New power plants are expected to consist of methane (built-in units of $100 \mathrm{MW}$ by 2025 and $250 \mathrm{MW}$ by 2050), peat (built-in units of $100 \mathrm{MW}$ ), hydro (two plants with installed capacity of $147 \mathrm{MW}$ and $287 \mathrm{MW}$ ), and an import of $300 \mathrm{MW}$ from neighboring countries. Peat, hydro and the import power is assumed to be added by 2050 [13], [18].

2) Medium Progression: The policy of distributing energy-saving compact fluorescent light (CFL) bulbs, which will lower electricity demand by increasing energy efficiency, is expected to be fully implemented by 2020 [19]. As a result, the annual lighting intensity is assumed to decrease to 300 $\mathrm{kWh}$ per household by 2050 in urban areas [19], [12]. The average adoption rate and new energy-saving attitude by customers is assumed to help in the reduction of annual refrigeration intensity to $140 \mathrm{kWh}$ per household by 2050 , whereas the use of other electricity-based equipment will continue to grow rapidly, at the same rate of $2.5 \%$ per year.

In rural areas, the energy intensity of electric lighting is expected to decrease by $1 \%$ per year. Due to rural development activities, the share of various cooking devices will change. By 2050, LPG stoves will be used by $35 \%$ of households and charcoal stoves by $15 \%$, while those with electric stoves are assumed to decrease to $20 \%$ in 2050 . The remaining rural households are assumed to use wood stoves [8], [11]. For the industry sector, the industrial development policy will continue to be implemented as defined in the low progression scenario. The total output for steel production is not expected to change. It is therefore assumed that all plants are operating at maximum capacity and no new plants are developed. Natural gas boilers, which are $10 \%$ more efficient than coal boilers, are assumed to be introduced and expected to provide $5 \%$ of the process heat requirements for steel production by 2050 [20]. However, tea expansion (in terms of area) is planned to be increased from the current 18,000 ha to around 25,000 ha. Two new tea factories will be completed and become operational: the first one by 2025 and the second one by 2030, with the addition of 10,000 tonnes of tea per year each to the total output of the tea production industry [21]. The outputs of the other industries are expected to grow at a rate of $1.5 \%$ per year, with the fuel share of electricity assumed to rise to $55 \%$ by 2050 . The strategic goals and objectives of the transport sector include implementing modern infrastructure, achieving cost-effective and quality services, while ensuring sustainable economic growth and developing an eco-friendly, safe and seamless integrated multimodal transport system for passengers and goods both at national and regional level.

The previous developments are estimated to result in a total increase in passenger capacity of 1\% until 2025 and
$1.5 \%$ until 2050 , with $65 \%$ of individual transport. The per capita demand for freight transport is assumed to grow at a rate of $1.5 \%$ per year over the analysis period, but the energy efficiency of all modes of transport (both passenger and freight) is expected to improve by $1 \%$ per year through 2050 as CNG buses are expected to be introduced. The exception is in passengers' cars, which are expected to have a growth of $0.2 \%$ per year due to the introduction of hybrid cars.

It is mandatory to explore mechanisms to improve modern energy services in rural areas by implementing the Second-Generation program (EDPRS). This program focuses on promising options for rural energy supply [9] (e.g. solar energy) and extension of the grid to rural areas. The $30 \mathrm{MW}$ of the existing diesel power plants are expected to be replaced by new solar farms and some home solar systems (HSS), where $15 \mathrm{MW}$ of the existing diesel plants are assumed to be retired by 2035 and the remaining $15 \mathrm{MW}$ by 2045 .

3) High Progression: New technology penetration is assumed to increase, where as part of the national electrification program the installation of efficient lighting systems could reduce the electricity consumed in urban and rural households due to the use of CFLs and other technologies. The program is reinforced in 2020 and is expected to reach around $75 \%$ of all urban and rural households by 2025 and $100 \%$ by 2035 [9]. A range of measures including new lighting standards and utility demandside-management programs are expected to reduce the energy intensity of electric lighting in urban households by $1 \%$ per year, and to reduce the expected growth in electric lighting intensity in rural areas to $0.3 \%$ per year [9]. The Government is considering introducing a new efficiency standard for refrigerators. This started in 2020, where by 2035 all urban refrigerators in the country (not rural) will be assumed to meet the new standard.

Proposed new efficiency standards for refrigerators are expected to cut the average energy intensities of refrigeration in urban households by $15 \%$ by 2025 compared to Current Accounts values, and by $60 \%$ in 2040 [8]. In rural households, the intensities are expected to decrease by $5 \%$ per year with the new efficiency standard for refrigerators adoption of $75 \%$ by 2050 [8].

\section{RESUlTS ANALYSIS AND DISCUSSION}

The Long range Energy Alternative Planning (LEAP) [22], which includes several built-in tools that help to easily create complex models and projections, was used to estimate the future of the electrical energy in Rwanda for a period of 30 years.

\section{A. Annual electrical energy demmand summary}

The annual electrical energy demand is considered as the sum of electricity demand from residential, industrial, transport and other sectors. Results have shown that across all the scenarios, the demand initially increases rapidly. However, due to the introduction of energy efficiency strategies by 2025 , this starts to be leveled down. By 2050, the total demand is the highest in the Basic Progression 
scenario at 7,906.3 $\mathrm{GWh}$, where electricity demand has increased to around $89 \%$. The High Progression scenario sees the lowest total demand in 2050 at $6,003 \mathrm{GWh}$. The total annual electrical energy demand increases year-on-year from 2019 , largely due to the electrification speed as the plan is to have $100 \%$ electricity access by 2024 . Fig. 2 . Illustrates the extent to which this trend continues across the scenarios and highlights the expected energy demand for different years towards 2050 .

\section{Energy Demand Final Units Fuel: Electricity}

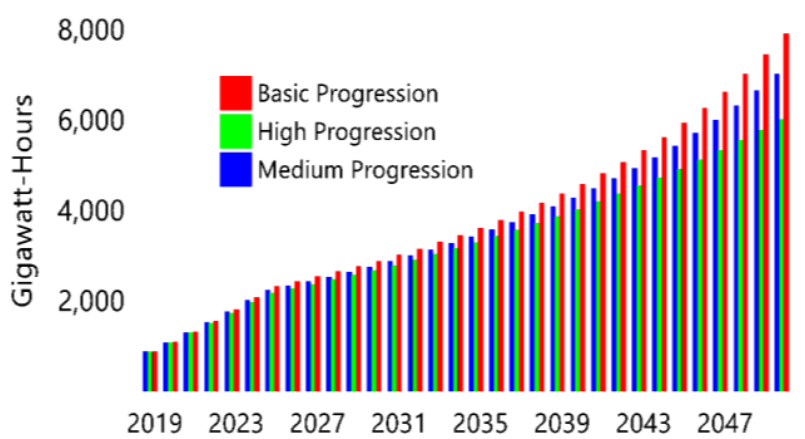

Fig. 2: The growth of electrical energy demand for each scenario

Year 2019 is considered as the base year. For each scenario, $54.3 \%$ of the total electrical energy demand of $873.3 \mathrm{GWh}$ was occupied by households, $17.1 \%$ by industry sector, $28.6 \%$ by the remaining. The residential sector is found to consume the most electrical energy but with a lower growth compared to other sectors in all scenarios. The following subsections illustrate the extent to which energy demand trends change across the three FES and highlights the contributions from each of the different energy sectors.

1) Basic Progresion: Results in Fig. 3 show that the total energy demand increases compared to today's level. This is due to the fact that driven by policy, economic and technological factors as well as consumer perception, consumers are likely to adopt lighting systems with cheap solutions but less efficiency. In addition, the appliances have low efficiency (e.g. refrigerators) and the improved transport (i.e. road-based public transport together with the introduction of electric vehicles -EVs-) is slowly adopted.

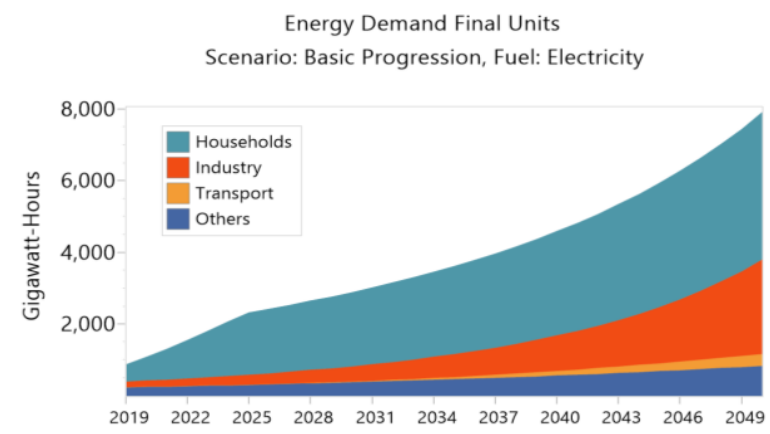

Fig. 3: Electricity annual demand by sector in basic progression scenario

2) Medium Progression: In this scenario, an increase in demand and the introduction of demand management measures are observed. This results in medium progression of low carbon technologies as the customers are more inclined to purchase larger and more efficient appliances. The electricity annual energy demand growth is shown in Fig. 4.

By 2030, it is estimated that the adoption of EVs in Rwanda's transport system starts to increase electricity demand as this outweighs effects of energy efficiency. However, this scenario sees the greatest reduction in total energy demand, falling to just $6800 \mathrm{GWh}$ by 2050, compared to the value of $7906 \mathrm{GWh}$ in basic progression. Energy Demand Final Units Scenario: Medium Progression, Fuel: Electricity

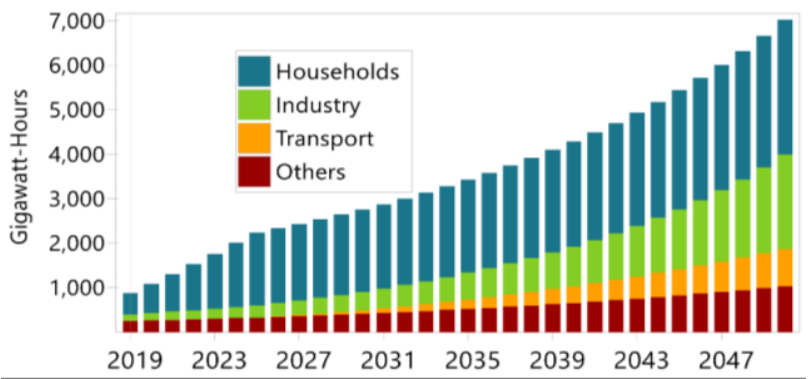

Fig. 4: Annual electricity demand by sector in medium progression scenario

3) High Progression: New measures including new lighting standards and demand-side-management programs are introduced to speed down the energy usage rate. Fig. 5 shows that the high progression scenario sees the lowest total demand in 2050 at $6,003.5 \mathrm{GWh}$. The factors that demonstrate this low energy demand include: demand-side management programs being fully adopted, a decrease in the average energy intensities of refrigeration, a reduction in the average energy intensity of electric lighting, and an improved transport system.

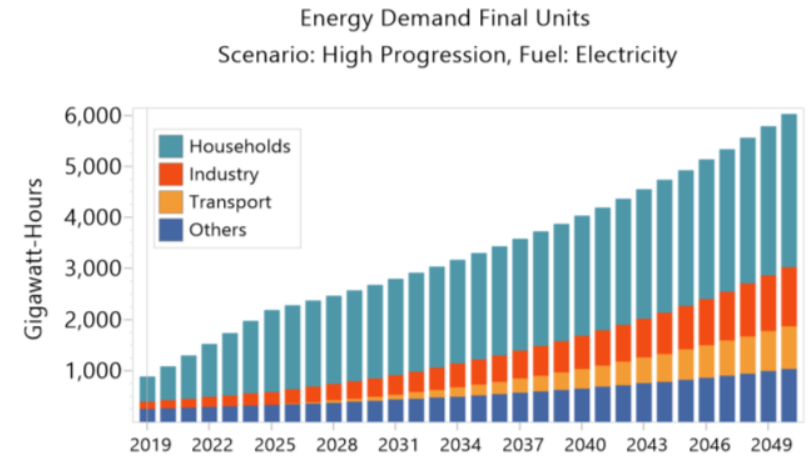

Fig. 5: Annual energy demand growth by sector in high progression scenario

\section{B. Electrical energy supply}

This section looks at Rwanda's electricity generation capacity, and how the annual output from this generation could change over the next 30 years. The study examines how various technologies could develop between now and 2050, considering the grid integration of renewable generation and electricity interconnectors. It discusses the development of the mix of generation technologies for each scenario. 
1) Basic Progression: It is shown in Fig. 6 that the generation capacity increases to around $1350 \mathrm{MW}$ by 2050 compared to the current total generation of around $220 \mathrm{MW}$. The results also show that the scenario adopts the use of low carbon technologies through a greater use of the available traditional electricity resources such as hydro, methane, peat, and biofuel, which in turn may contribute to Rwanda's emission reduction. However, diesel-based power plants are not expected to retire and, thus, they contribute to an increase in $\mathrm{CO}_{2}$ emissions.

\section{Capacity}

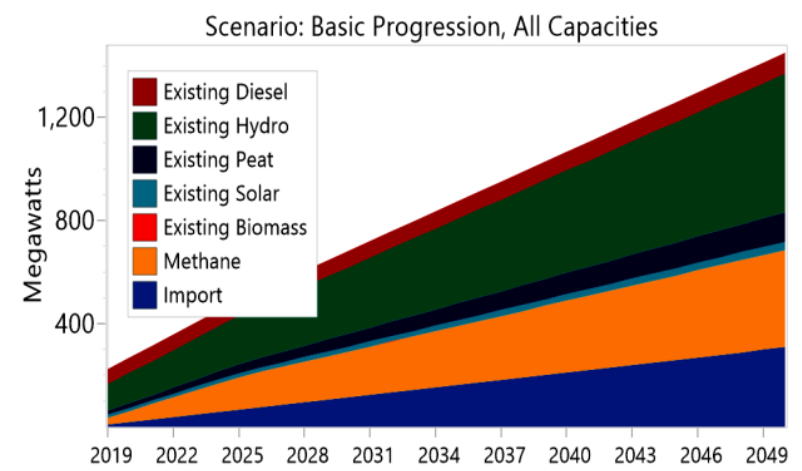

Fig. 6: Evolution in annual generation capacity by generation technology in basic progression scenario

2) Medium Progression: Fig. 7 shows how the installed generation capacity and generation technology mix could change in Rwanda over the next 30 years if some policies are implemented. The proportion of renewable capacity also grows, but much more quickly starting from 2020 . The results show a decrease in diesel-based power generation but at medium speed compared to the high progression scenario (shown next). A higher proportion of renewable generation is exhibited. Since much of this generation is intermittent, only electricity is produced during favorable weather conditions.

Capacity

Scenario: Medium Progression, Exogenous

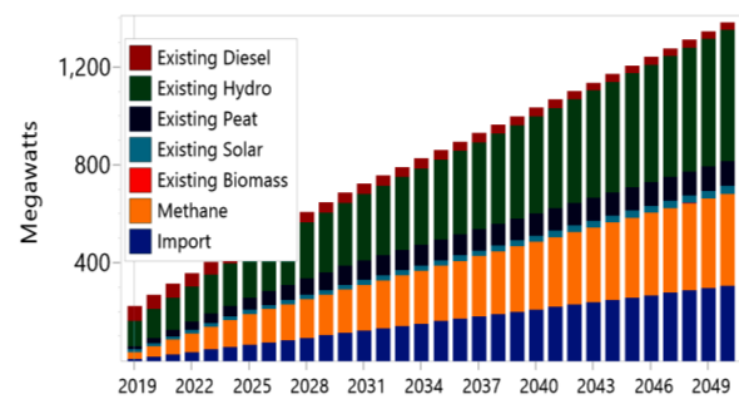

Figure 7: Generation capacity growth in medium progression scenario

3) High Progression: The large increase in output from hydro, and an increase in solar, means that by 2030, renewable generation could potentially account for almost $100 \%$ of the total electricity output.

Results in Fig. 8 show a significant decrease in dieselbased power plant where almost all plants are retiring by 2044.

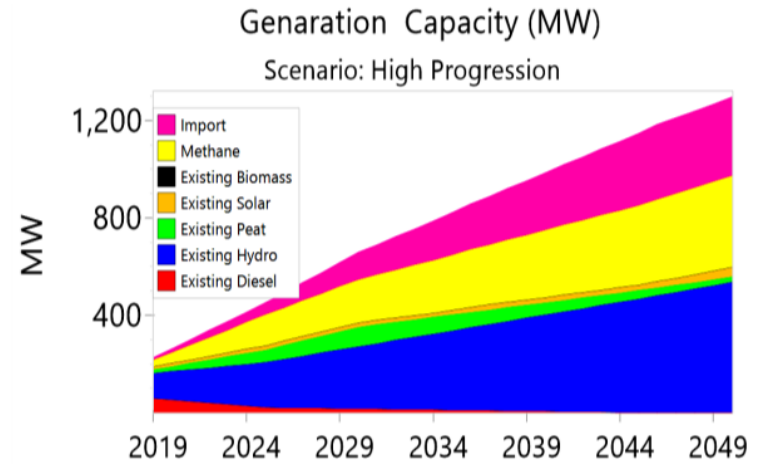

Fig. 8: Generation capacity growth in high progression scenario

\section{Greenhouse Gases Emissions}

High renewable energy generation penetration and the improved transport system are the largest contributors to the low increasing rate in $\mathrm{CO}_{2}$. According to Fig. 4, an electrification of transport is expected to be introduced by 2025. It is evident that the deployment of EVs and motorcycles, together with their charging technologies, will significantly reduce the dependence on fossil fuels, and hence $\mathrm{CO}_{2}$ emissions. Fig. 9 shows the $\mathrm{CO}_{2}$ emissions across different scenarios between 2020 and 2050 .

It is expected that reaching close to net-zero carbon emission by 2050 is achievable when the High Progression scenario is adopted. However, achieving this would require the retirement of fuel-based power plants and the immediate adoption of EVs in Rwanda's transport system.

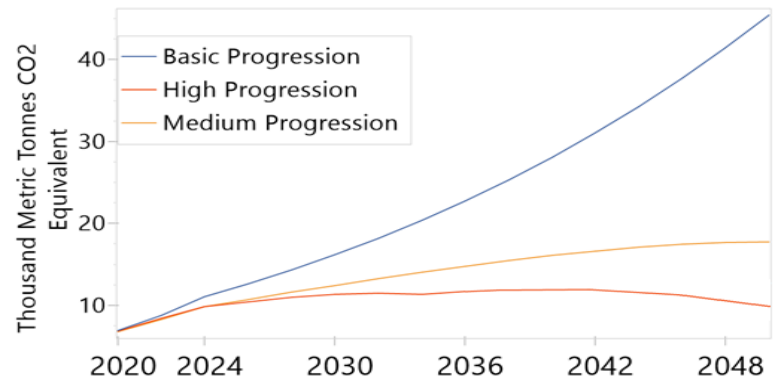

Fig. 9: Greenhouse gases emission in all FES.

IV. CONCUlusions

Energy is principal to Rwanda's economy and development plans. It supports all other sectors, including housing and urbanization, manufacturing, agro-processing, mining, tourism, and IT services. Therefore, a wellfunctioning, efficient, and emissions free energy sector is a precondition of achieving the country's goals. This paper suggests the developed FES that would support the Rwanda's long-term energy sector planning and investment by identifying sustainable options which will enhance Rwanda's energy security and mitigate climate change.

Basic progression scenario described the energy system with slow progression in low carbon technologies. In this basic progression scenario, driven by the policy, economic and technological factors as well as consumer perception, consumers are likely to adopt lighting systems with cheap solutions but less efficiency. It is assumed that renewable energy generation penetration is low, the appliances are with low efficiency (e.g. refrigerators) and the improved transport 
(i.e. road-based public transport together with the introduction of electric vehicles) is slowly adopted.

In the medium progression scenario, it is expected that: (i) the increase in demand, (ii) introduction of demand management measures and (iii) connection of renewable energy generation technologies, will result in medium progression of low carbon technologies as the customers are more inclined to purchase larger and more efficient appliances when the incomes rise.

In high progression scenario, the improved solutions in reducing carbon emission are implemented and consumers are supported to choose the options that could result in the high integration of low carbon technologies. Increasing renewable capacity, improving energy efficiency, and accelerating new technologies are policy priorities. In addition, new measures including new lighting standards and demand-sidemanagement programs are to be introduced to speed down the energy usage rate.

In general, results indicated that Rwanda has sufficient renewable energy resources to meet the projected electricity demand by 2050 and fossil fuel can be fully replaced with electricity sourced from hydropower combined with other indigenous sustainable energy resources. This is demonstrated in high progression scenario, where reaching around net-zero carbon emission by 2050 is achievable with some actions required to retire fuel-based power plants and the immediate action on the adoption of electric vehicles in Rwanda's transport system.

\section{ACKNOLEDGMENT}

The authors would like to thank MININFRA in Rwanda for providing the needed data. The authors also appreciate the Commonwealth Scholarship Commission in the UK for the financially supporting this work.

\section{REFERENCES}

[1] Rwanda Development Board (2018). Overview. Available online at: http://rdb.rw/investment-opportunities/energy/

[2] Ministry of Infrastructures, 25 September 2019. [Online]. Available: http://www.mininfra.gov.rw/index.php?id=83. [Accessed 25 September 2019].

[3] Ministry of Infrastructures of Rwanda's Energy Sector Strategic Plan 2013/14 - 2017/2018, Kigali, 2018.

[4] Rwanda Energy Group, Evolution of Power Transmission Network, November 2018.

[5] Uhorakeye, Theoneste. Modelling electricity supply options for Rwanda in the face of climate change. 2016. Thèse de doctorat. Zentrale Hochschulbibliothek Flensburg.

[6] USAID (2016). Rwanda Energy Sector Overview. Available online at: https://www.usaid.gov/sites/default/files/documents/1860/RwandaC ountryFactSheet_2016.09\%20FINAL.pdf
[7] Ministry of Infrastructures, Rwanda National Urbanization Policy, Kigali, September 2015.

[8] Ministry of Infrastructures, Rwanda National Cooling strategies, Kigali, 2019.

[9] Ministry of Infrastructures, Rwanda's Energy Sector Strategic Plan 2018/19 - 2023/24," Kigali, 2018.

[10] National Institute of Statistics of Rwanda, Rwanda National Statistical Yearbook, Kigali, 2013.

[11] M. Melin, Rwanda looks to market solutions to close clean cooking access-gap. [Online]. Available: https://www.seforall.org/news/

[12] B. Shepherd, Review of the Industrial policy in Rwanda, Data review, comparative assessment, and discussion option, November 2018.

[13] L. Horvath, Energy use in the steel industry, Iron and Steel Industry and process Integration Workshop, Tokyo, 2013.

[14] World Energy Council, World Energy Resources, 2016.

[15] R. J. Fruehan, "Theoretical Minimum Energies to Produce Steel, Report to the US Department of Energy, Office of Industrial Technologies," Washington, DC, 2000.

[16] Ministry of Infrastructures, Rwanda Transport Sector Strategic Plan for EDPRS2, Kigali, 2013.

[17] Ministry of Infrastructures, "Sustainable Energy for All Action Agenda 2016 Update," Kigali, 2016.

[18] World Bank, "Tracking SDG7: The Energy Progress Report 2019," June 2019.

[19] National Institute of Statistics of Rwanda, Rwanda Statistical Yearbook, Kigli, 2018.

[20] Rwanda Development Board (2018). Overview. Available online at: http://rdb.rw/investment-opportunities/energy/

[21] Ministry of Trade and Industry, Manufacturing Investment Opportunities in Rwanda," Kigali, 2014.

[22] Heaps C.G., 2016. Long-range Energy Alternatives Planning (LEAP) system. [Software version: 2018.1.40] Stockholm Environment Institute.Somerville,MA,USA.[Online]:Availablehttps://www.energyco mmunity.org.

[23] Ministry of Infrastructures, Sustainable Energy for All, rapid assessment, and gap analysis, Kigali, 2014. [Online]Available: https://energypedia.info/wiki/Rwanda_Energy_Situation.

[24] United Nations, Department of Economic and Social Affairs, Population Division (2019). World Population Prospects 2019, Online Edition. Rev. 1.

[25] Koema, Regional Transportation and Communication Statistics of Rwanda, 2018 [Online]. Available: https://knoema.com/NISRTCS2019

[26] Ministry of Infrastructures, Public Transport Policy and Strategy for Rwanda, Kigali, 2012.

[27] New Times Reporter, "Can construction industry lead the way in reducing import bill," Newtimes, January 17, 2015. [Online]. Available: https://www.newtimes.co.rw/section/read/185043. [Accessed May 26, 2020].

[28] Ministry of Infrastructures, Rwanda's Energy Sector Strategic Plan 2018/19 - 2023/24," Kigali, 2018. Available online at: https:/www.mini fra.gov.rw/index.php?id=energystrategicplan. 